\title{
Reconstructing individual food and growth histories from biogenic carbonates
}

\author{
Laure Pecquerie ${ }^{1,2, *}$, Ronan Fablet ${ }^{3,4}$, Hélène de Pontual ${ }^{5}$, Sylvain Bonhommeau ${ }^{6}$, \\ Marianne Alunno-Bruscia ${ }^{7}$, Pierre Petitgas ${ }^{8}$, Sebastiaan A. L. M. Kooijman ${ }^{9}$ \\ ${ }^{1}$ University of California Santa Barbara, Department of Ecology, Evolution and Marine Biology, Santa Barbara, \\ California 93106-9620, USA \\ ${ }^{2}$ IRD, UMR 212 EME, Centre de Recherche Halieutique Méditerranéenne et Tropicale, 34203 Sète, France \\ ${ }^{3}$ Telecom Bretagne, UMR CNRS 3192 Lab-STICC, 29230 Brest, France \\ ${ }^{4}$ Université Européenne de Bretagne, 35000 Rennes, France \\ ${ }^{5}$ Ifremer, Département Sciences et Technologies Halieutiques, 29280 Plouzané, France \\ ${ }^{6}$ Ifremer, UMR 212 EME, Centre de Recherche Halieutique Méditerranéenne et Tropicale, 34203 Sète, France \\ ${ }^{7}$ Ifremer, Département Physiologie des Organismes Marins, 29840 Argenton-Landunvez, France \\ ${ }^{8}$ Ifremer, Département Ecologie et Modèles pour l'Halieutique, 44300 Nantes, France \\ ${ }^{9}$ Vrije Universiteit, Department of Theoretical Biology, 1081 HV Amsterdam, The Netherlands
}

\begin{abstract}
Environmental conditions experienced by aquatic organisms are archived in biogenic carbonates such as fish otoliths, bivalve shells and coral skeletons. These calcified structures present an accretionary growth and variations in optical properties (color or opacity) that are used to reconstruct time. However, full and reliable exploitation of the information extracted from these structures is often limited as the metabolic processes that control their growth and optical properties are poorly understood. Here, we propose a new modeling framework that couples both the growth of a biogenic carbonate and its optical properties with the metabolism of the organism. The model relies on well-tested properties of the Dynamic Energy Budget (DEB) theory. It is applied to otoliths of the Bay of Biscay anchovy Engraulis encrasicolus, for which a DEB model has been previously developed. The model reproduces well-known otolith patterns and thus provides us with mechanisms for the metabolic control of otolith size and opacity at the scale of an individual life span. Two original contributions using this framework are demonstrated. (1) The model can be used to reconstruct the temporal variations in the food assimilated by an individual fish. Reconstructing food conditions of past and present aquatic species in their natural environment provides key ecological information that can be used to better understand population dynamics. (2) We show that non-seasonal checks can be discriminated from seasonal checks, which is a wellrecognized problem when interpreting fish otoliths. We suggest further developments of the model and outline the experimental settings required to test this new promising framework.
\end{abstract}

KEY WORDS: Otolith · Calcification · Metabolism · Bioenergetic model · Food reconstruction · Dynamic Energy Budget theory

Resale or republication not permitted without written consent of the publisher

\section{INTRODUCTION}

Calcified structures of aquatic species are remarkable archives of individual life histories and environmental conditions of past and present species. Based on increments that are periodically formed, age, growth, temperature conditions or migration patterns can be successfully reconstructed (e.g. Quinn et al. 1998, Tsukamoto et al. 1998, Schone et al. 2005). Although $\delta^{15} \mathrm{~N}$ analysis of bulk otolith material is difficult (Elsdon et al. 2010), some authors have also successfully reconstructed individual trophic position 
from otolith isotopic composition (Rowell et al. 2010). Extracting new information such as temporal variations of assimilated food would represent a remarkable new exploitation of these biogenic carbonates, and could, for example, contribute to a better understanding of the dynamics of a population.

A reliable interpretation of these calcified structures relies, however, on our understanding of biomineralization processes and how metabolism and environmental conditions control these processes. In fish and bivalve species, a strong link between carbonate growth and somatic growth has long been demonstrated (Campana 1990, Cerrato 2000). But it is well recognized that growth is not the only metabolic control of carbonate formation. Otolith and shell growth can be decoupled from somatic growth (Campana 1990, Lewis \& Cerrato 1997). Slow-growing individuals have somewhat larger otoliths than fastgrowing individuals of the same length, which can result in biased back-calculations of growth (Campana 1990). Moreover, a clear link between precipitation rate and metabolic rate has been established in corals (Al-Horani et al. 2005), bivalves (Lewis \& Cerrato 1997) and fish (Wright et al. 2001).

The objectives of the present study are twofold. (1) We investigate how metabolism controls the formation of biogenic carbonates from a bioenergetic modeling perspective. We explore in particular how starvation events may generate variations in carbonate optical properties and alter the seasonal deposition patterns. (2) We take advantage of the fact that carbonate formation depends not only on somatic growth but also on other metabolic processes and aim to demonstrate that growth as well as individual feeding history can be reconstructed from optical properties and growth measurements of biogenic carbonates.

Our new approach benefits from the conceptual and quantitative framework of the Dynamic Energy Budget (DEB) theory for metabolic organization (Kooijman 2010). This general theory describes the uptake and use of energy by an organism according to its environment throughout its life cycle to achieve growth and reproduction. It has been successfully applied to bivalves (e.g. van der Veer et al. 2006, Pouvreau et al. 2006), fish (e.g. van der Veer et al. 2001, Bodiguel et al. 2009, Pecquerie et al. 2009) and corals (Muller et al. 2009), but is applied here for the first time to the formation of a specific body part. The conceptual step that leads to a DEB-based model for biogenic carbonates is to consider them as metabolic 'products' (Kooijman 2010). The formation of any 'product' in the context of the DEB theory can poten- tially be linked to all metabolic functions, such as maintenance but also growth and assimilation (Kooijman 2010). Here, as investigated by Hüssy \& Mosegaard (2004) for otoliths of juvenile cod, we propose to link both the amount of material that precipitates and its optical properties to the metabolism of the organism. But, in contrast to the approach of Hüssy \& Mosegaard (2004), the present approach is parameter-sparse and simple in view of the number of patterns captured by the model over the life span of an individual.

In this paper, we first present the bioenergetic model for biogenic carbonate formation together with the food reconstruction method we developed. The model is then applied to the formation of fish otoliths and is validated by its ability to reproduce known patterns of otolith growth and opacity. Our method for the reconstruction of individual growth and feeding history is then evaluated from model simulations of individuals experiencing different food environments but presenting visually similar otoliths. We finally discuss the potential contributions of this new framework. It provides a way to better understand the complex interplay between metabolic and environmental controls of biogenic carbonate formation. But it also provides an opportunity to extract new key information from these labor-intensive data: the temporal variations of the food assimilated by individuals throughout their life cycle. We discuss the further model developments and the experimental data required to fully develop and validate this new promising method.

\section{MATERIALS AND METHODS}

\section{Standard DEB model}

DEB theory describes the rate at which an organism assimilates and utilizes energy and mass throughout its life cycle as a function of its state and its environment (i.e. food density and temperature) for maintenance, growth, development and reproduction (Fig. 1a) (Nisbet et al. 2000, Sousa et al. 2008, Kooijman 2010). An individual is described by 3 state variables: the reserve energy $E(\mathrm{~J})$, the structural volume $V\left(\mathrm{~cm}^{3}\right)$ and the reserve energy available for reproduction at the adult stage $E_{R}(\mathrm{~J})$. Stage transitions from embryo to juvenile and juvenile to adult occur at fixed structural volumes: at $V_{\mathrm{b}}$, the individual starts feeding; at $V_{\mathrm{p}}$, allocation to maturity is redirected to reproduction (subscripts $b$ and $p$ refer to birth and puberty, respectively). 
(a)

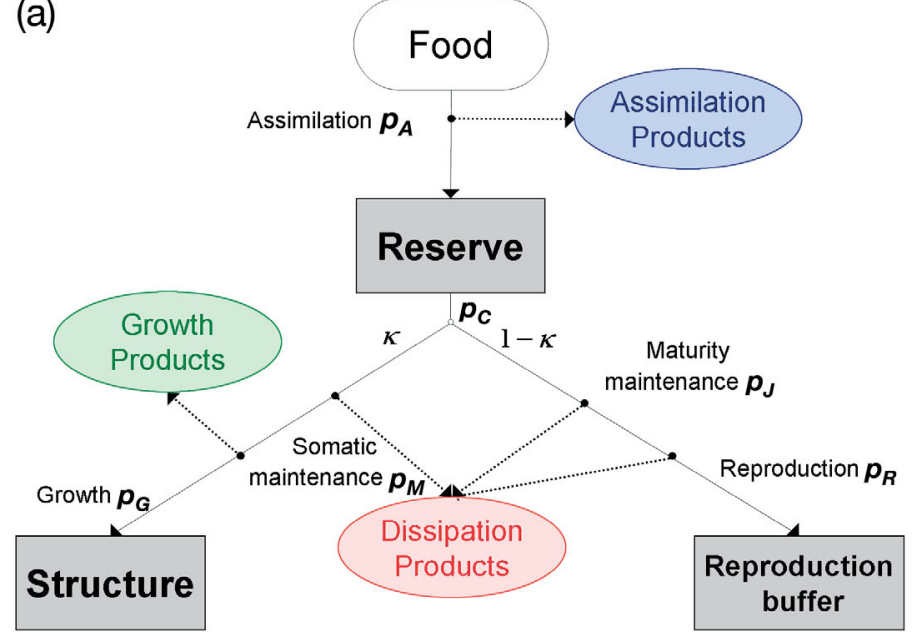

(b) $p_{A}$

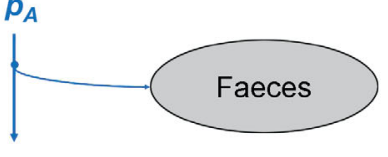

(c)

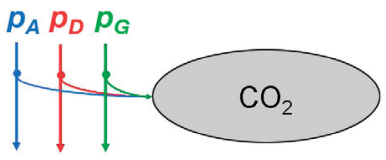

(d)

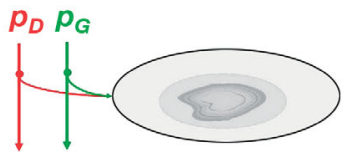

Fig. 1. (a) Energy and mass fluxes in a standard Dynamic Energy Budget model. The 3 organizing fluxes are represented: (1) assimilation $p_{A}$ (2) dissipation $p_{D}=$ somatic maintenance $p_{M}+$ maturity maintenance $p_{J}+$ development $p_{R}$ (embryo and juvenile), and (3) growth $p_{G}$. Three examples of metabolic 'products' are shown: (b) faeces, contribution from assimilation only; (c) $\mathrm{CO}_{2}$, contributions from the 3 transformations; and (d) carbonate structure (here an otolith), contributions from growth and dissipation

Three energy fluxes determine the dynamics of the state variables: assimilation $p_{A}$, growth $p_{G}$ and dissipation $p_{D}$ (Fig. 1a). The assimilation process $A$ transforms food into reserve and metabolic products (e.g. faeces and $\mathrm{CO}_{2}$ ) (Fig. 1b,c). The growth process $G$ transforms reserve into structure and metabolic products (e.g. $\mathrm{CO}_{2}$ ). The dissipation processes $D$ transform reserve into metabolic products (e.g. $\mathrm{CO}_{2}$ ) and energy used for maintenance and development processes. Somatic maintenance has priority over growth. In prolonged starvation conditions, i.e. when somatic maintenance costs cannot be covered by reserve energy, an adult can mobilize reserves previously allocated to reproduction $\left(E_{R}\right)$ to cover these somatic maintenance costs (Pouvreau et al. 2006, Pecquerie et al. 2009), but an individual would die if it is a juvenile, i.e. has no reproduction buffer, or if the reproduction buffer cannot cover somatic maintenance costs. Equations of the model are provided in Table 1 ; these equations are given for scaled state variables with no energy dimension (see Pecquerie et al. 2009).

\section{Biogenic carbonate formation}

Our objective was to link the accretion formation of a biogenic carbonate, i.e. the amount of material that precipitates as well as some optical properties of this material (opacity or color), to the metabolism of an organism. Our main assumption was that bio- genic carbonates can be defined as metabolic 'products' in the context of DEB theory (Fig. 1d). Like mammal hairs or tree bark, biogenic carbonates do not require maintenance. Hence they cannot be considered as part of the structural volume $V$ of an individual. They are also not readily available for growth or somatic maintenance and thus cannot be part of the reserve $E$.

We assumed that there is no remobilization of material once precipitated. Such remobilization, or dissolution, has only been suggested in extremely stressful conditions in otoliths (Mugiya \& Uchimura 1989) and in anaerobic conditions for bivalves (Rhoads \& Lutz 1980).

Product formation can be expressed as a weighted sum of the 3 organizing fluxes: assimilation, growth and dissipation (Kooijman 2010). The change in volume of a calcified structure $V_{\mathrm{C}}$ is thus given by:

$$
\frac{d}{d t} V_{\mathrm{C}}=\frac{1}{\left\{p_{A m}\right\}}\left(v_{A} p_{A}+v_{G} p_{G}+v_{D} p_{D}\right)
$$

where $v_{A}, v_{G}$ and $v_{D}$ are the coefficients $\left(\mathrm{cm} \mathrm{d}^{-1}\right)$ of the assimilation $A$, growth $G$ and dissipation $D$ contributions, respectively. Some of these coefficients can be zero, as shown in Fig. 1b for faeces production, which is coupled to assimilation only. As in Pecquerie et al. (2009), fluxes are scaled by $\left\{p_{A m}\right\}$, the maximum surface-area-specific assimilation rate, to remove the energy dimension. This scaling reduces the number of parameters to estimate; the flux equations in Table 1 are simplified when scaled by $\left\{p_{A m}\right\}$. 
Table 1. Variables, parameter values and equations for individual growth, maintenance and reproduction (from Pecquerie et al. 2009) and the otolith module (present study). Rates are given at the reference temperature $T_{1}=286 \mathrm{~K}\left(=13^{\circ} \mathrm{C}\right)$. Calibrated parameters are indicated (calib.)

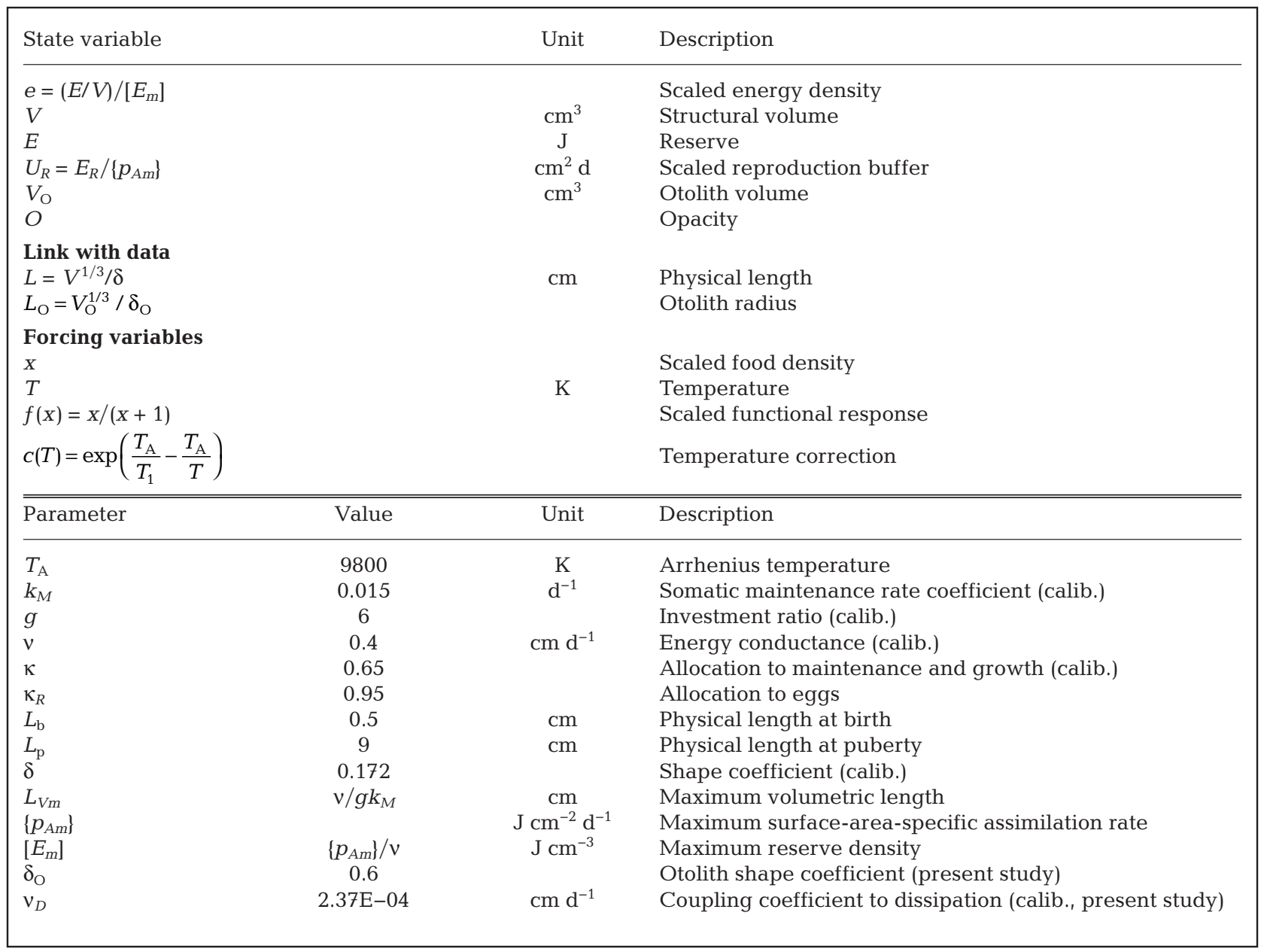

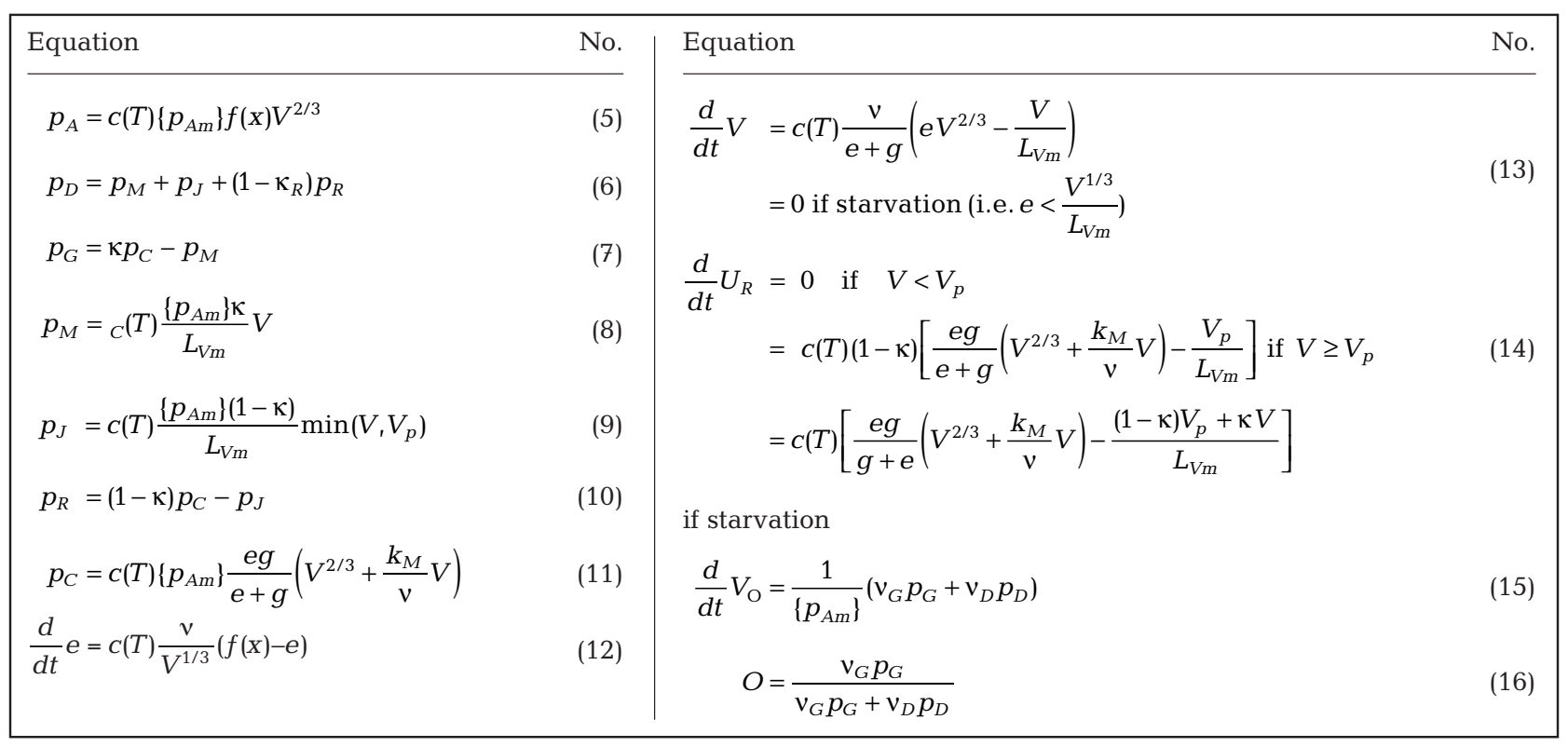


The contributions from the 3 organizing fluxes have different chemical compositions (Kooijman 2010) and may therefore contribute differently to the optical properties of the carbonate structure. The contribution of transformation $i(=A, D, G)$ to the opacity (or color) of the newly precipitated material $O_{i}$ is defined by:

$$
O_{i}(t)=\alpha_{i} \frac{v_{i} p_{i}}{\sum_{j=A, D, G} v_{j} p_{j}} \text { for } i=A, D, G
$$

Constants $\alpha_{i}$ can be set such that $O\left(=\Sigma_{i} O_{i}\right)$ values range between 0 and 1 .

We compared the properties of our model with stylized empirical patterns (sensu Sousa et al. 2008), i.e. patterns common to a range of taxa that we assume have similar underlying mechanisms (Table 2). Our approach is summarized in Fig. 2. Accordingly, the simulation of individual growth, carbonate growth and opacity as functions of temperature and food is referred as the 'forward' mode (Fig. 2a). The 'backward' mode, described in the following section, refers to the reconstruction of food and carbonate growth from carbonate features (e.g. opacity values along a given transect) (Fig. 2b).

\section{Reconstructing growth and food conditions}

The 'backward' mode allows us to reconstruct the age of an individual, its growth trajectory $L(t)$ and the scaled functional response $f(t)$, using opacity $O$ (or (a) 'Forward' mode

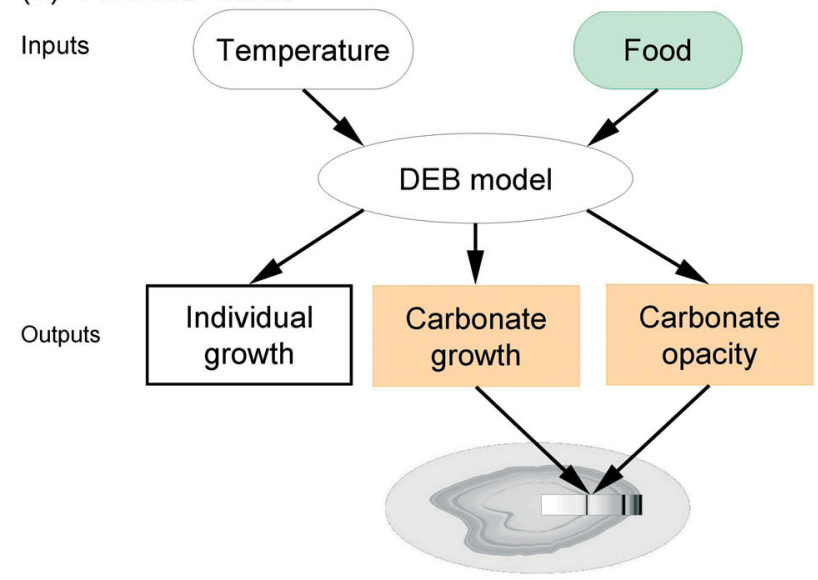

(b) 'Backward' mode

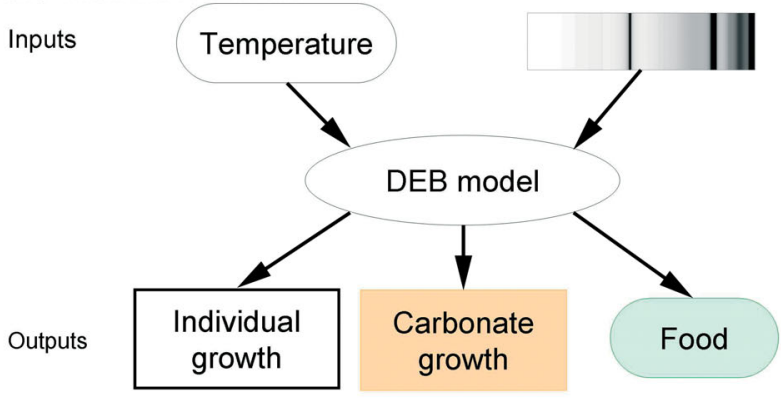

Fig. 2. (a) Approach to model the formation of a biogenic carbonate under metabolic control ('forward' mode). (b) Reconstruction of food conditions, individual and carbonate growth using the features of a biogenic carbonate (radius and opacity) and an average temperature function ('backward' mode)

Table 2. Stylized facts (S1 to S9; sensu Sousa et al. 2008) and empirical evidence on biogenic carbonate formation. Stylized facts are empirical patterns that we compare with properties of our model to evaluate the validity of our assumptions

Stylized facts $\quad$ Empirical evidence

\section{Biogenic carbonates}

S1 Carbonate growth is strongly related to somatic growth

S2 Carbonate growth is also correlated with metabolic rate

S3 Carbonates form seasonal rings

\section{Otoliths}

S4 Slow-growing individuals have larger otoliths than fast-growing fish of the same length

S5 Short starvation conditions do not modify otolith accretion rate

S6 Opacity decreases throughout ontogeny

S7 Opacity increases in colder temperatures

S8 Opacity decreases in poor feeding conditions

S9 Secondary structures can be formed
Fish: Campana (1990)

Bivalves: Cerrato (2000)

Fish: Yamamoto et al. (1998), Wright et al. (2001)

Bivalves: Lewis \& Cerrato (1997)

Corals: Al-Horani et al. (2005)

Fish: Campana (1990)

Bivalves: Lewis \& Cerrato (1997), Wanamaker et al. (2008)

Corals: Quinn et al. (1998)

Campana (1990)

Neat et al. (2008)

Hoff \& Fuiman (1993)

Mosegaard \& Titus (1987), Neat et al. (2008)

Neilson \& Geen (1985), Hoie et al. (2008)

Panfili et al. (2002) 
color) measured along a transect of the carbonate structure of length $L_{\mathrm{C}}$ (Fig. 2). We made the following assumptions: (1) the parameters in Table 1 are known (i.e. previously estimated) for a given reference temperature $T_{1}$ together with the coefficients $v_{i}$ $(i=A, D, G)$, (2) the temperature experienced by the individual is known, and (3) the carbonate structure is isomorphic and the relationship between the transect length of the carbonate structure $L_{C}$ and its volume $V_{\mathrm{C}}$ is known: $V_{\mathrm{C}}=\left(\delta_{\mathrm{C}} L_{\mathrm{C}}\right)^{3}$, where $\delta_{\mathrm{C}}$ is the carbonate structure shape coefficient.

The reconstruction is defined as the determination of the feeding values minimizing the square deviation between the observed and the predicted opacity (or color) values. This minimization was carried out using a forward gradient-based approach: at each step, given current estimates of the state variables $V_{\text {, }}$ the structural volume, and $e$, the scaled reserve density, at time $t_{\mathrm{k}}$, we estimated the scaled functional response $f_{k}$ that minimize the square deviation between predicted and observed carbonate length and opacity (or color) $\left(L_{C(k+1)}, O_{k+1}\right)$ using Eqs. $(12,13,15$ \& 16) (Table 1). We obtained $V_{k+1}$ and $e_{k+1}$. This method requires an initialization for $V$, e and $t$ at the first data point $\left(L_{\mathrm{C}} O\right)$. This initialization depends on the application and is detailed below for fish otoliths. Given the estimated series $f$, we can deduce the scaled food density $x(t)$ the organism experienced as follows:

$$
x(t)=\frac{X(t)}{K}=\frac{f(t)}{1-f(t)}
$$

where $X$ is the food density and $K$ is the saturation constant.

All computations for the reconstruction were performed with the routine 'o2f' in the 'animal' toolbox of the software package 'DEBtool' for Octave and MATLAB. The package is freely downloadable from www.bio.vu.nl/thb/deb/deblab/.

\section{Application to fish otoliths}

Our model for biogenic carbonates was applied to the formation of a sagitta, the largest otolith among the 3 otolith pairs located in the inner ear of fish. Our assumption to consider the otolith as a product is fully consistent with Wright et al. (2001) and Yamamoto et al. (1998), who showed a close correlation between otolith growth and $\mathrm{O}_{2}$ consumption rates (S2, Table 2). As DEB theory also implies that $\mathrm{O}_{2}$ consumption is a weighted sum of assimilation, dissipation and growth processes (Kooijman 2010), the cor- relation between $\mathrm{O}_{2}$ consumption and formation of products such as otoliths is reproduced.

We assumed that assimilation does not contribute to otolith accretion, i.e. $v_{A}=0$ (Eq. 15 in Table 1), as short starvation periods do not modify otolith accretion rates (S5, Table 2) (Neat et al. 2008). Thus, opacity can be expressed as follows:

$$
O=\frac{\alpha_{G} v_{G} p_{G}+\alpha_{D} v_{D} p_{D}}{v_{G} p_{G}+v_{D} p_{D}}
$$

To reproduce translucent bands during slowgrowing periods (S8, Table 2), we chose the simplest form of the opacity function, i.e. $\alpha_{G}=1$ and $\alpha_{D}=0$ (Eq. 16 in Table 1). Thus, opacity is decreasing when growth is slowing down and opacity is equal to zero when the individual ceases growth, i.e. when $p_{G}=0$. Although choosing such a simple opacity function removes one parameter $\left(\alpha_{D}\right)$, it impedes the reconstruction of the feeding conditions when the individual is not growing (in structure). In this case, i.e. when $p_{G}=$ 0 , we can only state that the scaled functional response $f$ is lower than $V^{1 / 3} / L_{\mathrm{m}}$ (Eq. 13), but we cannot estimate its value. The value $f=V^{1 / 3} / L_{\mathrm{m}}$ corresponds to the minimum food level required to cover somatic maintenance costs; below this level, we assume that maintenance costs are covered by the reserves previously allocated to reproduction, if available (Pouvreau et al. 2006, Pecquerie et al. 2009). If no reserves are available, the individual dies.

Regarding initialization, a simple approach is to start from a stage transition for which the average length $L$ is documented. Here, we considered the length at the initiation of feeding (referred to as birth), $L_{\mathrm{b}}$ (Table 1). If a specific check can be attributed to initiation of feeding in larval otolith (e.g. Rae et al. 1999, Lee \& Kim 2000), otolith radius at birth $L_{\mathrm{Ob}}$ is known. The scaled reserve density at birth $e_{\mathrm{b}}$ is obtained by minimizing the square deviation between the observed and the predicted opacity $O_{\mathrm{b}}$ (Eq. 16 in Table 1). The average water temperature at the peak of the spawning period can be taken as the temperature at birth, $T_{\mathrm{b}}$ as a first approximation.

\section{Application to the Bay of Biscay anchovy}

We applied the model to the Bay of Biscay anchovy Engraulis encrasicolus, which is a small pelagic fish species with a short life span $(4 \mathrm{yr})$. Adult and juvenile data were collected during Ifremer spring acoustic surveys (PEL.2001 to 2005) and an autumn survey (JUVESU1999). Individual data on length (total length [TL], to the nearest $5 \mathrm{~mm}$ ), 
age (in days for juveniles, in number of winters for adults, e.g. a Group 1 [G1] individual experienced 1 winter) and otolith radius (nearest $\mu \mathrm{m}$ ) were collected. Data collection and measurement methods are fully described in Petitgas \& Grellier (2003) and Allain et al. (2003). As anchovy otoliths are observed in reflected light (e.g. Cermeño et al. 2003), translucent bands appear dark in our simulations (Fig. 2).

Parameters of the DEB model for anchovy growth and reproduction (Table 1) were taken from Pecquerie et al. (2009). We only need to estimate 3 new parameters: $\delta_{O}$, the otolith shape coefficient, and $v_{G}$ and $v_{D}$, the coefficients associated with growth and dissipation, respectively (Table 1 ). We need to estimate $\delta_{\mathrm{O}}$ to relate otolith radius (observation) to otolith volume (model variable): $V_{\mathrm{O}}=\left(\delta_{\mathrm{O}} L_{\mathrm{O}}\right)^{3}$. We used $W_{\mathrm{O}}=d_{\mathrm{VO}}\left(\delta_{\mathrm{O}} L_{\mathrm{O}}\right)^{3}$, where $W_{\mathrm{O}}$ is the otolith weight $(\mathrm{g})$ and $d_{\mathrm{VO}}\left(2.9 \mathrm{~g} \mathrm{~cm}^{-3}\right)$ is the otolith density (Carlström 1963). For a $12 \mathrm{~cm}$ standard length (SL) anchovy, which corresponds to $14 \mathrm{~cm}$ TL (Wysokinski 1986), Lychakov \& Rebane (2005) found $W_{\mathrm{O}}=$ $0.002402 \mathrm{~g}$. Using the linear relationship we determined for adult Bay of Biscay anchovy $L_{\mathrm{O}}=0.0402+$ $0.0082 L\left(\mathrm{r}^{2}=0.77, \mathrm{p}<0.001, \mathrm{n}=3452\right)$, we obtained an average otolith radius $L_{O}$ of $0.155 \mathrm{~cm}$ and a shape coefficient $\delta_{\mathrm{O}}$ of 0.6 .
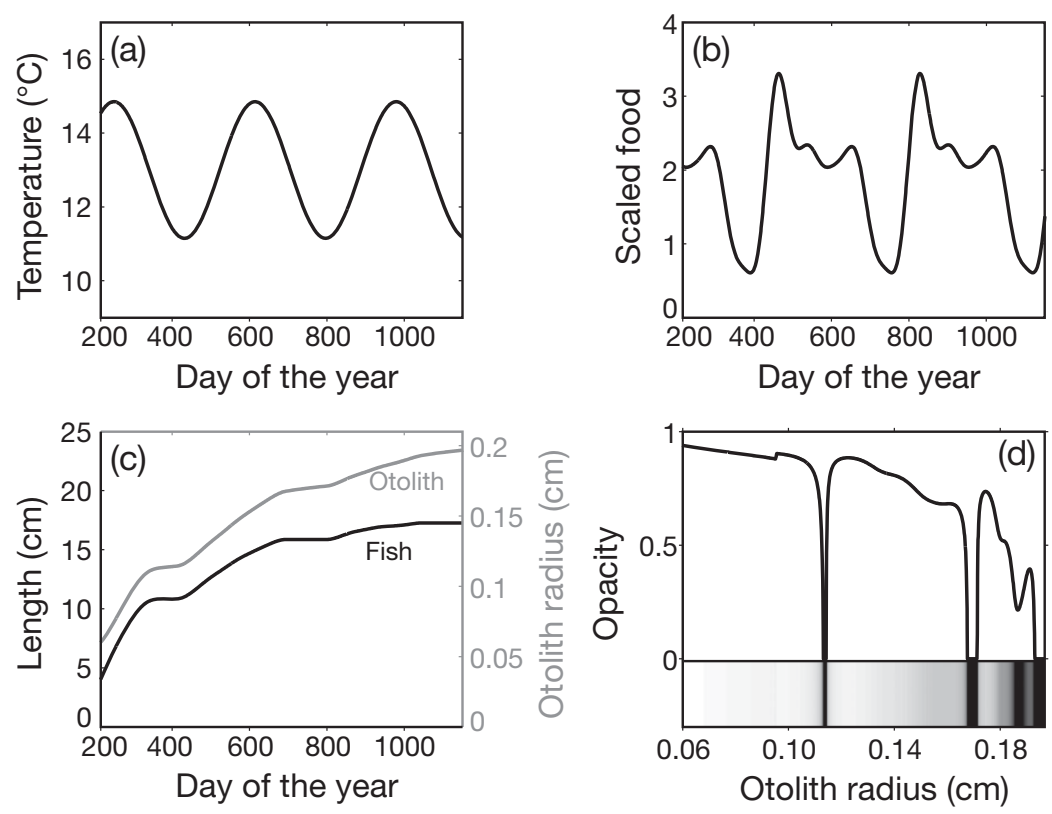

Fig. 3. Simulation of fish growth and otolith formation for a 3 yr-old individual that experienced seasonal environment variations (Simulation 1): (a) temperature, (b) scaled food density, and (c) fish length (black line) and otolith radius (grey line) as functions of time (days of the year continuously counted for $3 \mathrm{yr}$ ) and (d) opacity as a function of otolith radius and corresponding image (translucent bands appear dark as if observed in reflected light)
To estimate $v_{\mathrm{G}}$ and $v_{\mathrm{D}}$, we simulated the body growth and otolith growth of a G3 individual and minimized the difference between the observed average otolith radius $L_{\mathrm{O}}(\mathrm{cm})$ at a given length $L(\mathrm{~cm})$ and the predicted value at the sampling date (1 June). The observed otolith radius $L_{\mathrm{O}}$ at length $L$ is computed using the linear relationship mentioned above for adult Bay of Biscay anchovy. The same environmental conditions (Fig. 3a,b) and the same initial conditions at metamorphosis on 1 August $(t=0)$ as in Pecquerie et al. (2009) were used: $L(0)=4 \mathrm{~cm}$, $e(0)=f(0)$ and $U_{R}(0)=0 \mathrm{~cm}^{2} \mathrm{~d}$. The initial otolith radius, i.e. at metamorphosis, $L_{\mathrm{O}}(0)=0.06 \mathrm{~cm}$ was obtained from the linear relationship between otolith radius and individual length fitted to juvenile data in the range 3.5 to $4.5 \mathrm{~cm}\left(L_{O}=0.0203 L-0.0239, \mathrm{n}=34\right.$, $\mathrm{r}^{2}=$ 0.825; see Fig. 1.10 in Pecquerie 2008).

\section{Simulation design}

In Simulation 1, we studied the opacity pattern of an otolith transect from an individual that experienced the seasonal temperature and food conditions used in the parameter estimation procedure (Fig. 3a,b).

In Simulation 2, we compared the observed and predicted average otolith radii of individuals of the same lengths but different ages (G1 and G2, 1 and 2 winters of age, respectively). We expected larger otolith radius in slow-growing individuals (G2) compared with fast-growing individuals (G1) of the same length (e.g. Campana 1990). We simulated the growth of 200 individuals. Individuals randomly hatch between 1 April and 15 August, which corresponds to the spawning season of the Bay of Biscay anchovy population (Motos et al. 1996). Hatching dates were drawn from a normal distribution with a mean of 1 June (day of the year 152) and a standard deviation of $25 \mathrm{~d}$. We used the same seasonal temperature and food conditions as in Simulation 1, but some noise was introduced in each food and temperature trajectory. G1 and G2 individuals were caught on a random date in May, i.e. the period of annual Ifremer surveys. We then computed the average otolith radius per age and size class of these 200 fish. 


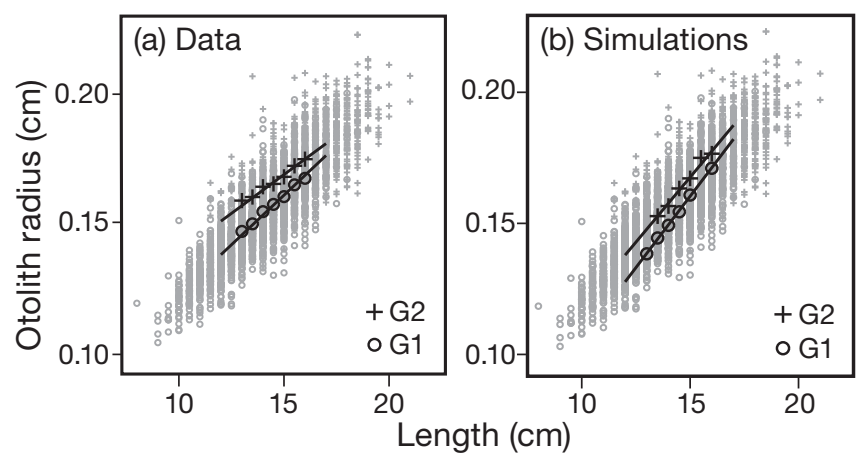

Fig. 4. Average otolith radius (black $\mathrm{O}$ and + ) per age and fish length class $(0.5 \mathrm{~cm})$ for the range 13 to $16 \mathrm{~cm}$ from (a) data for the Bay of Biscay anchovy Engraulis encrasicolus and (b) Simulation 2. Grey $O$ and + represent the complete data set of G1 (age 1) and G2 (age 2) individuals collected between 2001 and 2005, given in both panels for comparison
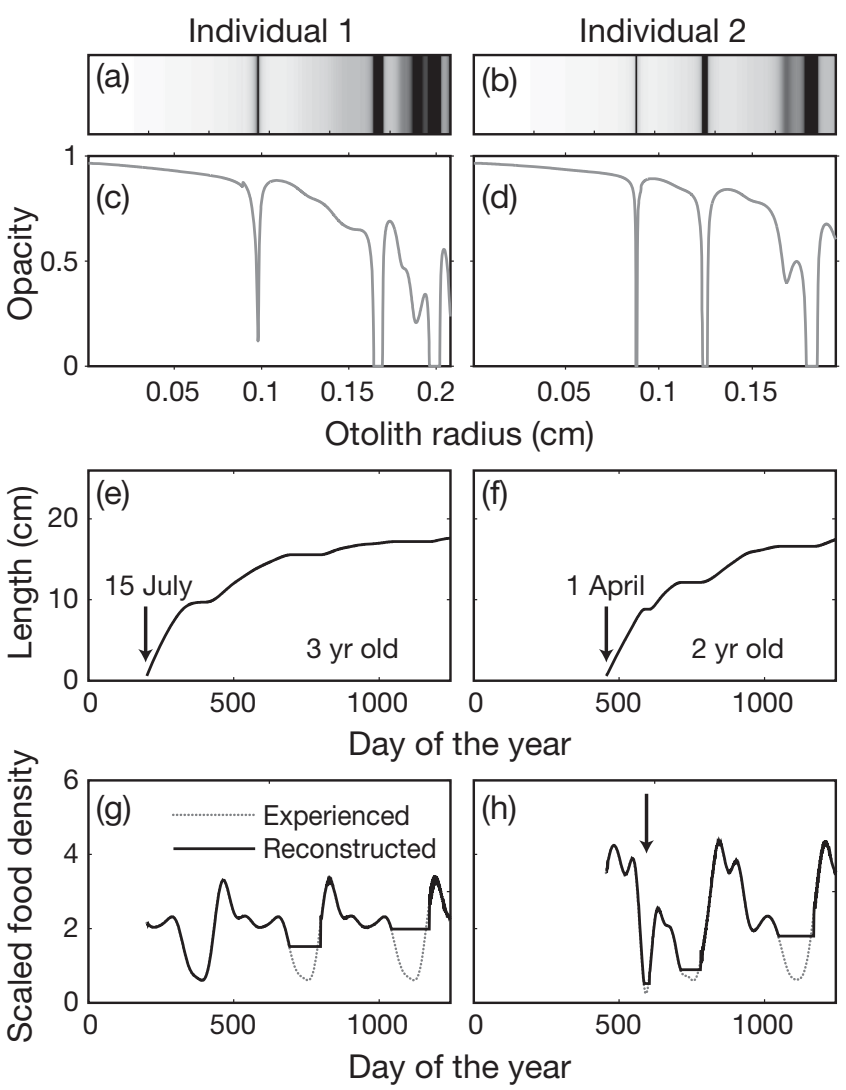

Fig. 5. Reconstruction of growth and scaled food densities experienced by 2 fish that present translucent zones in their otoliths and that could be both interpreted as G3 fish (Simulation 3). (a,b) Images of the simulated otolith opacity transects for Individuals 1 and 2, respectively. (c,d) Corresponding opacity as a function of otolith radius. $(\mathrm{e}, \mathrm{f})$ Realized and reconstructed growth. Reconstructed growth fully overlapped the realized growth for both individuals. $(g, h)$ Experienced and reconstructed scaled food densities. Thick arrow in (h): starvation period that led to a secondary structure in the otolith of Individual 2. In $(\mathrm{e}, \mathrm{f})$, days of year are continuously counted for $3 \mathrm{yr}$
In Simulation 3, we first investigated the conditions for formation of secondary structures, i.e. translucent bands that are not annual rings (Panfili et al. 2002), under starvation conditions ('forward' mode, Fig. 2a). Second, we tested the ability of the 'backward' mode to detect such secondary structures and differentiate otoliths with similar patterns. Two individuals were simulated: Individual 1 hatches in Year 0 late in the season (15 July) whereas Individual 2 hatches earlier in the season (1 April) the following year (Year 1). Initial conditions were set at the initiation of feeding: $e_{\mathrm{b}}=f, V_{\mathrm{b}}, U_{R \mathrm{~b}}=0$ and we set $L_{\mathrm{Ob}}=0.001 \mathrm{~cm}$ for both individuals, which is within the range of otolith radii observed for anchovy larvae at mouth opening (data from Allain et al. 2003). The 2 individuals experienced the seasonal temperature conditions used in Simulation 1 (Fig. 3a). Whereas Individual 1 experiences the food conditions used in Simulation 1 (Fig. 3b), Individual 2 experiences better food conditions but a sharp decrease in food conditions before its first winter. The sampling date was set at 1 June of Year 3. The 'backward' mode for the reconstruction of feeding history was then applied to both opacity profiles (Fig. 2b) and reconstructed feeding histories are compared with 'experienced' values ('forward' mode, Fig. 2a).

\section{RESULTS}

\section{Decoupling between otolith and somatic growth}

A 'forward' simulation of the model using realistic average environmental conditions (Fig. 3a,b) quantitatively reproduced well the observed otolith growth patterns of the Bay of Biscay anchovy (Figs. 3c \& 4). The simulated individual has a length of ca. $17 \mathrm{~cm}$ and an otolith radius of $0.2 \mathrm{~cm}$ after 3 growing periods (Fig. 3c), which is within the range of observed values, 0.16 to $0.21 \mathrm{~cm}$, for a $17 \mathrm{~cm}$ fish (Fig. 4a). However, the predicted otolith radius of small fish were smaller than observed (Fig. 4). The slope of the otolith radius to fish length (OR-FL) relationship is then larger than the observed slope, e.g. 0.011 and 0.008, respectively, for G1 individuals. The linear OR-FL relationship is nonetheless well reproduced for a large range of anchovy lengths.

Most interestingly, the decoupling between otolith and somatic growth is also quantitatively well reproduced (Fig. 4), although no constraint was added in the parameter estimation procedure to reproduce this observation. This decoupling results in G2 (slowgrowing) fish having larger otoliths than G1 (fast- 
growing) fish of the same length. In the data, $90 \%$ of the G1 and the G2 individuals range between 11 and $16 \mathrm{~cm}$ and 13 and $18.5 \mathrm{~cm}$, respectively. We thus computed the average otolith radius for each $0.5 \mathrm{~cm}$ length class where G1 and G2 individuals are both observed (13 to $16 \mathrm{~cm}$ Fig. 4a). We found significant differences between average otolith radius of G1 and G2 individuals of the same length in the data ( $t$-tests per length class had p-values $<0.01$ ). The model successfully reproduced the observed difference for each simulated length class (Fig. 4b). Average differences between otolith radius of fish of the same length but different ages are $75 \mu \mathrm{m}$ in the data and $73 \mu \mathrm{m}$ in the simulation. The variability in the OR-FL relationship was, however, lower in our simulation than in the observations as fewer individuals were simulated (Fig. 4b).

\section{Opacity patterns}

The model reproduced alternated opaque and translucent zones (Fig. 3d) as observed opacity patterns in anchovy otoliths (Cermeño et al. 2003). In addition, we noticed an overall decrease of the opacity through ontogeny (Fig. 3d), which is commonly observed (Panfili et al. 2002).

A particularly interesting feature of the model is its ability to generate secondary structures. In Simulation 3 , the 2 otoliths presented 3 translucent zones and their radii were similar: 2.1 and $1.9 \mathrm{~mm}$ for Individuals 1 and 2, respectively (Fig. 5c,d). These otoliths could both be interpreted as G3 individuals. However, the first translucent zone on the otolith transect of Individual 2 corresponds to a secondary structure (Fig. 5b). This 'check' was generated by stressful feeding conditions (thick arrow, Fig. 5h). During this period, the fish stopped growing for $16 \mathrm{~d}$ while some translucent material was still deposited, which contributed to the growth of the otolith (Fig. $5 \mathrm{~b}, \mathrm{f}$ ). It should be noted that early hatching date in the season associated with better feeding conditions for Individual 2 (thin lines, Fig. 5g,h) explains why Individuals 1 and 2 have similar otolith sizes despite their difference in age (Fig. 5e,f).

\section{Assimilated food can be quantified from otolith size and opacity}

The application of the 'backward mode' to these 2 individuals was successful (black lines, Fig. 5e,f): both individual ages and growth patterns were correctly recovered. We also successfully reconstructed the dynamics of the respective feeding histories. When growth completely ceases, the reconstruction method attributes a ceiling value to the assimilated food level (black lines, Fig. 5g,h). As the individual gets larger, this ceiling value increases: maintenance costs are proportional to structural volume (Eq. 8) and thus the minimum food requirements increase as well.

\section{DISCUSSION}

In the present study, we developed a modeling tool based on DEB theory to better understand metabolic control on the formation of biogenic carbonates. We showed that the potential of this model is the extraction of new key information from these structures: the food assimilated by individuals in their natural environment. The originality of the approach relies on the assumption that biogenic carbonates can be modeled as metabolic DEB 'products'. Application of this approach to the formation of fish otoliths resulted in a simple model that reproduces known patterns of otolith growth and opacity. The model provides a mechanistic basis for understanding (1) the decoupling between fish length and otolith radius, (2) the overall decrease in opacity as the otolith grows and (3) the formation of secondary structures in stressful conditions.

\section{A parameter-sparse model consistent with otolith growth patterns}

The resulting bioenergetic model for otolith growth and opacity is a simple model that relies on one key assumption - an otolith is a metabolic 'product'—and 3 additional parameters, $\delta_{O}, v_{G}$ and $v_{D}$ (Table 1), once the bioenergetic model for fish growth and reproduction is calibrated (Pecquerie et al. 2009). DEB theory recognizes 2 compartments (reserve and structure) instead of 1 (weight) to represent an organism. Some body parts, however, do not follow the definition of structure and reserve: they are not readily available for growth or somatic maintenance (reserve) and do not require maintenance (structure). These body parts can thus be referred as metabolic products, although they are not exchanged with the environment. The formation of these body parts can then be linked to one or more metabolic transformations (Kooijman 2010).

Which transformation contributes to the formation of a specific metabolic product is not prescribed and should be guided by empirical patterns (Table 2). For 
our otolith application, we assumed that assimilation does not contribute to otolith formation, which simplified greatly the parameter estimation but was not obligatory. This assumption is nonetheless consistent with starvation experiments (Neat et al. 2008) and varying feeding frequency experiments (Oyadomari \& Auer 2007) that showed no effect on otolith growth and opacity.

By assuming that otolith accretion is coupled not only to somatic growth but also to dissipation processes, the model provides mechanisms for the relationship between somatic growth and otolith accretion. (1) The contribution from dissipation processes is small compared with the contribution from growth $\left(v_{G}\right.$ $>v_{D i}$ Table 1). Thus, a tight correlation between otolith radius and fish length, consistent with otolith data (Campana 1990), was obtained despite the fact that no fixed relationship between these quantities is assumed in the model. (2) The contribution from dissipation processes, though small, explains the well-known decoupling between somatic growth and otolith accretion. The overall contribution of the somatic growth process to the total accretion of the otolith is the same when fish have the same length and does not depend on the time required to reach this length. In contrast, the contribution from dissipation processes is larger in older fish as it is integrated over a longer time period. This results in slow-growing fish having larger otoliths than fast-growing fish of the same length, which has been widely observed (e.g. Campana 1990). This decoupling is particularly significant for large and/or old fish during slow-growing periods because (1) maintenance processes are continuous processes that contribute to otolith accretion even if somatic growth ceases and (2) as an individual becomes larger, its maintenance costs increase and so does the contribution from dissipation to otolith accretion.

In our simulation, we obtained smaller than observed otoliths for small fish (Fig. 4). By increasing the relative contribution from dissipation compared with growth and assuming that small fish could survive longer in limiting food conditions, we could potentially improve the fit to the data. However, this requires more detailed work on starvation rules from data that were not available to us.

\section{Metabolism-induced variations in opacity are also consistent with otolith data}

By linking opacity to the relative contribution of the growth process, the model reproduces the observations that both juvenile and adult fish develop opaque, high-contrast otoliths during periods of high growth, and translucent, low-contrast otoliths during unfavorable growth conditions or starvation (Neilson \& Geen 1985, Rice et al. 1985). The underlying mechanism in our model is the following: the chemical composition of the contributions from growth and dissipation is different. Therefore, the chemical composition of the material that precipitates varies according to the relative strength of these 2 processes. Dannevig (1956) showed a link between otolith organic content, consisting of amino acids, and opacity. This observation has since been confirmed: translucent structures are dominated by aragonitic calcium crystals, whereas protein fibers dominate opaque structures (Mugiya 1965, Watabe et al. 1982, Hüssy et al. 2004). Our model is consistent with the mentioned studies. The contributions from growth and dissipation may, for instance, differ in their protein content, both qualitatively and quantitatively. At this stage, however, we refrain from making this link explicitly for simplicity's sake.

The model also provides mechanisms for both the formation of secondary structures and the overall decrease in opacity as an individual grows. The formation of secondary structures is still poorly understood (Panfili et al. 2002), but the misinterpretation of such structures leads to age and growth estimation errors (de Pontual et al. 2006). Here, in agreement with the assumption formulated by Hoie et al. (2008), we show that a severe decrease in food conditions can generate a translucent zone that could be interpreted as a winter ring. Furthermore, as the fish becomes larger, the specific growth rate decreases and the dissipation flux increases because of increased somatic maintenance costs (Eq. 8 in Table 1). The decreasing and increasing contributions from growth and dissipation, respectively, to otolith formation result in a decrease in opacity (Eq. 16 in Table 1).

The model, however, does not reproduce the decrease in opacity observed in individuals experiencing higher temperatures (Mosegaard \& Titus 1987, Otterlei et al. 2002, Neat et al. 2008). As temperature impacts metabolic processes in the same way as in the standard DEB model, the temperature effect on metabolic fluxes currently cancels itself out in the opacity function (Eq. 16 in Table 1). Introducing a temperature-specific effect on $\mathrm{CaCO}_{3}$ precipitation would improve the present model. The precipitation rate of pure aragonite minerals, the normal calcium carbonate polymorph in otoliths, has been shown to increase with temperature (Burton \& Walter 1987). Specifying different equations for the organic and the mineral fractions, however, requires additional 
parameters and specific data sets of opacity measurements in different controlled environments that are not currently available for the European anchovy.

\section{Parameter estimation and validation experiments}

In this study, we used DEB parameters previously estimated for anchovy (Pecquerie et al. 2009). As state variables of the standard DEB model (reserve and structure) are unobservable, estimating DEB parameters for a given species can be challenging. We here refer the reader to a number of studies specifically dedicated to DEB parameter estimation (van der Meer 2006, Kooijman et al. 2008, Lika et al. 2011) and to a comparison between traditional bioenergetic models and DEB models with a particular emphasis on fish models (Nisbet et al. in press). DEB parameters are typically estimated simultaneously by minimizing a weighted sum of squared deviations between a number of data sets and model predictions on feeding, growth, development and reproduction. The sum of squared deviations is typically weighted depending on the number of data points per data set and the relevance of the data set (Lika et al. 2011). For fish applications, data such as length-at-age, weight-length relationships and length-fecundity relationships are required (Pecquerie et al. 2009, Lika et al. 2011). In addition, data on age, length and weight at stage transitions (hatching, first-feeding, metamorphosis and first reproduction) are particularly useful, together with egg descriptors (wet or dry weight, energy content) (Pecquerie et al. 2009, Lika et al. 2011).

To validate our approach and carefully estimate otolith parameters, opacity measurements from controlled experiments are required together with fish length at different points in time. These experiments would ideally be performed over a sufficiently long period to observe variations in growth rates (in length) at the individual scale following variations in food and temperature conditions. As mentioned in the previous section, these data were not available for the European anchovy. Such a data set, however, is available for cod Gadus morhua (Hoie et al. 2008). Applying our approach to cod nonetheless requires the estimation of cod-specific DEB parameters, which was beyond the scope of the present study. We hope the promising results we obtained will motivate such future work.

Regarding data comparison, the strength of our approach is the possibility to compare a simulated transect and real data in one dimension. To do so, we simulate the total volume of an otolith and assume an isomorphic growth. A single parameter then describes the link between otolith radius and volume. A coupling of our approach with a two-dimensional representation of a biogenic carbonate, as developed by Fablet et al. (2009) for otoliths, could help resolve situations where the isomorphic growth assumption does not apply, as found for cod Gadus morhua and whiting Merlangius merlangus otoliths (Fablet et al. 2009) and mussel Mytilus edulis shell in some conditions (Alunno-Bruscia et al. 2001) .

\section{Comparison with other modeling approaches}

Compared with other bioenergetic models for otolith formation (Schirripa \& Goodyear 1997, Hüssy \& Mosegaard 2004), the main difference in our approach is that weight and respiration are not taken as explanatory variables. In a DEB context, growth only refers to the growth in length and not the growth in weight, for instance. Other processes, such as assimilation or reproduction, can be involved in changes in weight. Not differentiating between different metabolic components was presented by Hüssy \& Mosegaard (2004) as one of the limitations of their approach. Here, metabolic components that control otolith growth can be differentiated.

Schirripa \& Goodyear (1997) suggested that the geometry of the fish body versus the otolith, i.e. the difference between the otolith radius:otolith weight exponent and the fish length:fish weight exponent, was a crucial factor in determining the OR-FL relationship and in explaining the decoupling between otolith radius and fish length. They emphasized, however, that back-calculating length with their approach might require the use of different weight-length relationships, e.g. gonad production generates variations in weight that should not be taken into account to backcalculate length. Our approach overcomes this problem and provides a different mechanism for the decoupling between fish length and otolith radius: dissipation processes also contribute to otolith growth.

Our approach also provides a new interpretation of the experiments conducted by Neat et al. (2008). These authors suggested that somatic growth and otolith accretion and opacity were not causally related in the short term. A 2 wk starvation experiment on large juvenile cod showed no effect on otolith accretion rate and opacity, although the individuals were losing weight (Neat et al. 2008). Reserve acts as a buffer to food variations in our model and the larger the individual, the larger the lag response to food variations. Thus, growth (of structure) continues dur- 
ing short starvation periods in large individuals if they have sufficient reserve. As the loss of reserve is larger than the gain in structure, weight decreases. But as growth and dissipation still occur, otolith growth and opacity may not be significantly affected during these short starvation periods.

\section{Reconstructing growth and food conditions in natural environments}

In the present work, we show that our approach can be used to estimate fish age and back-calculate growth in length ('backward' mode) at a much finer scale than the annual pattern. Reconstructing the duration of the non-growing periods (Hüssy \& Mosegaard 2004) and detecting secondary structures (de Pontual et al. 2006) can be of great value for fisheries research, e.g. to estimate temporal variability of survival probability or reduce misinterpretations that result in biased age and growth estimation.

But we also show that new key information can potentially be extracted from otolith growth and opacity: the food assimilated by the individual throughout its life span. For instance, the energy available to reproduction in natural conditions could in turn be deduced from assimilated food. This method thus can potentially improve the estimation of some demographic parameters and contribute to a better understanding of population dynamics. The specific structure of the model with 2 state variables to represent biomass and a reserve compartment that buffers food fluctuations in particular are key to reconstruct the feeding history. Without the reserve compartment, we would not be able to reconstruct assimilated food.

Few methods are available to quantitatively characterize feeding in natural conditions over an extended period. In marine mammals and seabirds, stomach temperature recorders have pioneered our ability to document feeding. The magnitude or duration of the temperature change in the stomach is assumed to be proportional to the amount of food consumed. Yet these devices have limitations (e.g. Ropert-Coudert \& Kato 2006) and are not available for ectotherms and small organisms in particular. We believe our approach has the potential to overcome these drawbacks. It could also complement stable isotope analysis studies, which characterize the qualitative aspects of feeding, in a quantitative way to learn more about temporal resource dynamics and, for example, size-dependent food selection.

In our reconstruction method, we assumed that the temperature conditions were known. This would re- quire measurements of the oxygen isotope ratio $\delta^{18} \mathrm{O}$, for instance (e.g. Campana 1999, Quinn et al. 1998). It should be noted, however, that our method is not very sensitive to temperature variations experienced by the individual (not shown). Although the data we generated in the forward mode stemmed from a smooth seasonal temperature cycle, we obtained reasonable results using a constant temperature throughout the individual life span in the backward mode.

Although we demonstrate the potential of this approach, it requires validation using opacity measurements in controlled conditions with known food and temperature conditions. Data on cod Gadus morhua could be used, as otolith data and fish growth data are available from the same experimental settings where groups of individuals experience different controlled food and temperature in time and fish growth is measured both in weight and length (e.g. Li et al. 2008).

\section{Further application of the model: the effect of ocean acidification on biocalcifying organisms}

In the context of ocean acidification due to increased levels of atmospheric $\mathrm{CO}_{2}$, a better understanding of the metabolic control on biogenic carbonates formation could be of great value to distinguish the direct effect of lowered $\mathrm{pH}$ on $\mathrm{CaCO}_{3}$ dissolution and an indirect effect on calcification through metabolic responses. Reduced biomineralization of $\mathrm{CaCO}_{3}$ due to lowered $\mathrm{pH}$ has been observed in mollusks and corals (e.g. Comeau et al. 2009, Cohen et al. 2009). Some studies have shown no effect of ocean acidification on otolith formation, e.g. in juveniles of the spiny damselfish Acanthochromis polyacanthus (Munday et al. 2011). However, Checkley et al. (2009) and McDonald et al. (2009) have shown unexpected patterns, i.e. enhanced calcification in the otoliths of white sea bass Atractoscion nobilis and the shell of the barnacle Amphibalanus amphitrite. If one can assume that stressful conditions owing to lowered $\mathrm{pH}$ increase maintenance processes, our approach suggests that an increase in calcification could be observed. Dissolution processes might, however, counteract this effect and be predominant in numerous species. The approach we developed provides a framework where $\mathrm{pH}$ conditions could impact $\mathrm{CaCO}_{3}$ precipitation both directly and indirectly via their impact on metabolic processes. We strongly believe that this approach represents a promising starting point to disentangle and quantify these different impacts of ocean acidification on biogenic carbonate formation and biocalcifying organisms in general. 
Acknowledgements. This work was supported by Ifremer, CLPMEM of Saint-Gilles-Croix-de-Vie and La Turballe, the UE projects FISBOAT and RECLAIM (FP6 contracts no. 502572 and 44133) and the NSF grants EF-0742521 and DEB-0717259. The authors thank the participants of the PELGAS surveys and P. Grellier for data collection and interpretation; the members of the European Research Group AquaDEB (www.ifremer.fr/aquadeb), S. Campana, D. Kaplan and B. Ananthasubramaniam for helpful discussions; and R. Nisbet and four anonymous reviewers for helpful comments on an earlier version of the manuscript.

\section{LITERATURE CITED}

Al-Horani FA, Al-Rousan SA, Manasrah RS, Rasheed MY (2005) Coral calcification: use of radioactive isotopes and metabolic inhibitors to study the interactions with photosynthesis and respiration. Chem Ecol 21:325-335

> Allain G, Petitgas P, Grellier P, Lazure P (2003) The selection process from larval to juvenile stages of anchovy (Engraulis encrasicolus) in the Bay of Biscay investigated by Lagrangian simulations and comparative otolith growth. Fish Oceanogr 12:407-418

> Alunno-Bruscia M, Bourget E, Frechette M (2001) Shell allometry and length-mass-density relationship for Mytilus edulis in an experimental food-regulated situation. Mar Ecol Prog Ser 219:177-188

Bodiguel X, Maury O, Mellon-Duval C, Roupsard F, Le Guellec AM, Loizeau V (2009) A dynamic and mechanistic model of PCB bioaccumulation in the European hake (Merluccius merluccius). J Sea Res 62:124-134

> Burton EA, Walter LM (1987) Relative precipitation rates of aragonite and $\mathrm{Mg}$ calcite from seawater: temperature or carbonate ion control? Geology 15:111-114

- Campana SE (1990) How reliable are growth back-calculation based on otoliths? Can J Fish Aquat Sci 47: 2219-2227

Campana SE (1999) Chemistry and composition of fish otoliths: pathways, mechanisms and applications. Mar Ecol Prog Ser 188:263-297

Carlström D (1963) A crystallographic study of vertebrate otoliths. Biol Bull 125:441-463

Cermeño P, Uriarte A, de Murguia AM, Morales-Nin B (2003) Validation of daily increment formation in otolith of juvenile and adult European anchovy. J Fish Biol 62: 679-691

> Cerrato RM (2000) What fish biologists should know about bivalve shells. Fish Res 46:39-49

> Checkley DM, Dickson AG, Takahashi M, Radich JA, Eisenkolb N, Asch R (2009) Elevated $\mathrm{CO}_{2}$ enhances otolith growth in young fish. Science 324:1683

> Cohen AL, McCorkle DC, de Putron S, Gaetani GA, Rose KA (2009) Morphological and compositional changes in the skeletons of new coral recruits reared in acidified seawater: insights into the biomineralization response to ocean acidification. Geochem Geophys Geosyst 10: Q07005, doi:10.1029/2009GC002411

Comeau S, Gorsky G, Jeffree R, Teyssie JL, Gattuso JP (2009) Impact of ocean acidification on a key Arctic pelagic mollusc (Limacina helicina). Biogeosciences 6: 1877-1882

Dannevig EH (1956) Chemical composition of the zones in cod otoliths. J Cons Int Explor Mer 21:156-159

de Pontual H, Groison AL, Pineiro C, Bertignac M (2006) Evi- dence of underestimation of European hake growth in the Bay of Biscay, and its relationship with bias in the agreed method of age estimation. ICES J Mar Sci 63: 1674-1681

- Elsdon TS, Ayvazian S, McMahon KW, Thorrold SR (2010) Experimental evaluation of stable isotope fractionation in fish muscle and otoliths. Mar Ecol Prog Ser 408:195-205

Fablet R, Chessel A, Carbini S, Benzinou A, de Pontual H (2009) Reconstructing individual shape histories of fish otoliths: a new image-based tool for otolith growth analysis and modeling. Fish Res 96:148-159

Hoff GR, Fuiman LA (1993) Morphometry and composition of red drum otoliths: changes associated with temperature, somatic growth rate, and age. Comp Biochem Physiol A 106:209-219

Hoie H, Folkvord A, Mosegaard H, Li L, Clausen LAW, Norberg B, Geffen AJ (2008) Restricted fish feeding reduces cod otolith opacity. J Appl Ichthyology 24:138-143

> Hüssy K, Mosegaard H (2004) Atlantic cod (Gadus morhua) growth and otolith accretion characteristics modelled in a bioenergetics context. Can J Fish Aquat Sci 61: 1021-1031

> Hüssy K, Mosegaard H, Jessen F (2004) Effect of age and temperature on amino acid composition and the content of different protein types of juvenile Atlantic cod (Gadus morhua) otoliths. Can J Fish Aquat Sci 61:1012-1020

Kooijman SALM (2010) Dynamic energy and mass budgets in biological systems, 3rd edn. Cambridge University Press, Cambridge

Kooijman SALM, Sousa T, Pecquerie L, van der Meer J, Jager T (2008) From food-dependent statistics to metabolic parameters, a practical guide to the use of dynamic energy budget theory. Biol Rev Camb Philos Soc 83: 533-552

> Lee TW, Kim GC (2000) Microstructural growth in otoliths of black rockfish, Sebastes schlegeli, from prenatal larval to early juvenile stages. Ichthyol Res 47:335-341

> Lewis DE, Cerrato RM (1997) Growth uncoupling and the relationship between shell growth and metabolism in the soft shell clam Mya arenaria. Mar Ecol Prog Ser 158: 177-189

Li L, Hoie H, Geffen AJ, Heegaard E, Skadal J, Folkvord A (2008) Back-calculation of previous fish size using individually tagged and marked Atlantic cod (Gadus morhua). Can J Fish Aquat Sci 65:2496-2508

Lika K, Freitas V, van der Veer HW, van der Meer J, van der Wijsman JWM, Pecquerie L, Kearney MR, Kooijman SALM (2011) The 'covariation method' for estimating the parameters of the standard Dynamic Energy Budget model. I: philosophy and approach. J Sea Res 66:270-277

> Lychakov DV, Rebane YT (2005) Fish otolith mass assymetry: morphometric and influence on acoustic functionality. Hear Res 201:55-69

McDonald MR, McClintock JB, Amsler CD, Rittschof D, Angus RA, Orihuela B, Lutostanski K (2009) Effects of ocean acidification over the life history of the barnacle Amphibalanus amphitrite. Mar Ecol Prog Ser 385:179-187

Mosegaard H, Titus R (1987) Daily growth rates of otolith yolk sac fry of two salmonds at five different temperatures. In: Kullander SO, Fernholm N (eds) Proc 5th Congr European Ichthyologists. Swedish Museum of Natural History, Stockholm, p 221-227

Motos L, Uriarte A, Valencia V (1996) The spawning environment of the Bay of Biscay anchovy (Engraulis encrasicolus L.). Sci Mar 60:117-140 
Mugiya Y (1965) Calcification of fish and shellfish. X. Study on paper electrophoretic patterns of the acid mucopolysaccharides and Pas-positive materials in the otolith fluid of some fish. Bull Jpn Soc Sci Fish 32:653-661

> Mugiya Y, Uchimura T (1989) Otolith resorption induced by anaerobic stress in the goldfish Carassius auratus. J Fish Biol 35:813-818

Muller EB, Kooijman SALM, Edmunds PJ, Doyle FJ, Nisbet RM (2009) Dynamic energy budgets in syntrophic symbiotic relationships between heterotrophic hosts and photoautotrophic symbionts. J Theor Biol 259:44-57

Munday PL, Gagliano M, Donelson JM, Dixson DL, Thorrold SR (2011) Ocean acidification does not affect the early life history development of a tropical marine fish. Mar Ecol Prog Ser 423:211-221

Neat FC, Wright PJ, Fryer RJ (2008) Temperature effects on otolith pattern formation in Atlantic cod Gadus morhua. J Fish Biol 73:2527-2541

Neilson JD, Geen GH (1985) Effects of feeding regimes and diel temperature cycles on otolith increment formation in juvenile Chinook salmon, Oncorhynchus tshawytscha. Fish Bull 83:91-101

> Nisbet RM, Muller EB, Lika K, Kooijman SALM (2000) From molecules to ecosystems through dynamic energy budget models. J Anim Ecol 69:913-926

Nisbet RM, Jusup M, Klanjscek T, Pecquerie L (in press) Integrating dynamic energy budget (DEB) theory with traditional bioenergetic models. J Exp Biol

Otterlei E, Folkvord A, Nyhammer G (2002) Temperature dependent otolith growth of larval and early juvenile Atlantic cod (Gadus morhua). ICES J Mar Sci 59:851-860

Oyadomari JK, Auer NN (2007) Influence of rearing temperature and feeding regime on otolith increment deposition in larval ciscoes. Trans Am Fish Soc 136:766-777

Panfili J, Troadec H, de Pontual H, Wright PJ (eds) (2002) Manual of fish sclerochronology. Ifremer-IRD coedition, Brest, France

Pecquerie L (2008) Bioenergetic modelling of the growth, development and reproduction of a small pelagic fish: the Bay of Biscay anchovy. PhD thesis, Vrije Universiteit, Amsterdam, http://dare.ubvu.vu.nl/handle/1871/11716

Pecquerie L, Petitgas P, Kooijman SALM (2009) Modeling fish growth and reproduction in the context of the dynamic energy budget theory to predict environmental impact on anchovy spawning duration. J Sea Res 62: 93-105

Petitgas P, Grellier P (2003) Size selective processes for anchovy in Biscay, 2000-2002: recruitment, adult survival and spawning. ICES CM 2003/N:07, ICES, Tallin

> Pouvreau S, Bourles Y, Lefebvre S, Gangnery A, AlunnoBruscia M (2006) Application of a dynamic energy budget model to the Pacific oyster, Crassostrea gigas, reared under various environmental conditions. J Sea Res 56: 156-167

Quinn TM, Crowley TJ, Taylor FW, Henin C, Joannot P, Join $\mathrm{Y}$ (1998) A multicentury stable isotope record from a New Caledonia coral: Interannual and decadal sea surface temperature variability in the southwest Pacific since 1657 AD. Paleoceanography 13:412-426

Editorial responsibility: Stylianos Somarakis, Heraklion, Greece
Rae GA, San Román NA, Spinoglio DE (1999) Age validation and growth of yolked larvae of Patagonotothen tessellata (Richardson, 1845) (Pisces: Nototheniidae) from the rocky littoral of the Beagle Channel, Argentina. Sci Mar 63:469-476

Rhoads DC, Lutz RA (1980) Skeletal growth of aquatic organisms: biological records of environmental change. Plenum Press, New York

Rice JA, Crowder LB, Binkowski FP (1985) Evaluating otolith analysis for bloater Coregonus hoyi: do otoliths ring true? Trans Am Fish Soc 114:532-539

Ropert-Coudert Y, Kato A (2006) Are stomach temperature recorders a useful tool for determining feeding activity? Polar Biosci 20:63-72

> Rowell K, Dettman D, Dietz R (2010) Nitrogen isotopes in otoliths reconstruct ancient trophic position. Environ Biol Fishes 89:415-425

> Schirripa MJ, Goodyear CP (1997) Simulation of alternative assumptions of fish otolith-somatic growth with a bioenergetics model. Ecol Model 102:209-223

Schone BR, Fiebig J, Pfeiffer M, Gless R and others (2005) Climate records from a bivalved Methuselah (Arctica islandica, Mollusca; Iceland). Palaeogeogr Palaeoclimatol Palaeoecol 228:130-148

> Sousa T, Domingos T, Kooijman SALM (2008) From empirical patterns to theory: a formal metabolic theory of life. Philos Trans R Soc Lond B 363:2453-2464

> Tsukamoto K, Nakai I, Tesch WV (1998) Do all freshwater eels migrate? Nature 396:635-636

> van der Meer J (2006) An introduction to dynamic energy budget (DEB) models with special emphasis on parameter estimation. J Sea Res 56:85-102

> van der Veer HW, Kooijman SALM, van der Meer J (2001) Intra- and interspecific comparison of energy flow in North Atlantic flatfish species by means of dynamic energy budgets. J Sea Res 45:303-320

> van der Veer HW, Cardoso JFMF, van der Meer J (2006) The estimation of DEB parameters for various Northeast Atlantic bivalve species. J Sea Res 56:107-124

Wanamaker AD, Heinemeier J, Scourse JD, Richardson CA, Butler PG, Eiriksson J, Knudsen KL (2008) Very longlived mollusks confirm 17th century AD Tephra-based radiocarbon reservoir ages for North Icelandic shelf waters. Radiocarbon 50:399-412

> Watabe N, Tanaka K, Yamada J, Dean JM (1982) Scanning electron microscope observations of the organic matrix in the otolith of the teleost fish Fundulus heteroclitus (Linnaeus) and Tilapia nilotica (Linnaeus). J Exp Mar Biol Ecol 58:127-134

> Wright PJ, Fallon-Cousins P, Armstrong JD (2001) The relationship between otolith accretion and resting metabolic rate in juvenile Atlantic salmon during a change in temperature. J Fish Biol 59:657-666

Wysokinski A (1986) The living marine resources of the Southeast Atlantic. FAO Fish Tech Pap (178) Rev. (1). FAO, Rome

Yamamoto T, Ueda H, Higashi S (1998) Correlation among dominance status, metabolic rate and otolith size in masu salmon. J Fish Biol 52:281-290

Submitted: March 23, 2011; Accepted: November 10, 2011 Proofs received from author(s): January 28, 2012 